\title{
Stomatin-Related Olfactory Protein, SRO, Specifically Expressed in the Murine Olfactory Sensory Neurons
}

\author{
Ko Kobayakawa, Reiko Hayashi, Kenji Morita, Kazunari Miyamichi, Yuichiro Oka, Akio Tsuboi, and \\ Hitoshi Sakano \\ Department of Biophysics and Biochemistry, Graduate School of Science, University of Tokyo, Bunkyo-ku, Tokyo \\ 113-0032, Japan
}

\begin{abstract}
We identified a stomatin-related olfactory protein (SRO) that is specifically expressed in olfactory sensory neurons (OSNs). The mouse sro gene encodes a polypeptide of 287 amino acids with a calculated molecular weight of $32 \mathrm{kDa}$. SRO shares $82 \%$ sequence similarity with the murine stomatin, $78 \%$ with $\mathrm{Cae}-$ norhabditis elegans MEC-2, and 77\% with C. elegans UNC-1. Unlike other stomatin-family genes, the sro transcript was present only in OSNs of the main olfactory epithelium. No sro expression was seen in vomeronasal neurons. SRO was abun-
\end{abstract}

dant in most apical dendrites of OSNs, including olfactory cilia. Immunoprecipitation revealed that SRO associates with adenyIyl cyclase type III and caveolin-1 in the low-density membrane fraction of olfactory cilia. Furthermore, anti-SRO antibodies stimulated CAMP production in fractionated cilia membrane. SRO may play a crucial role in modulating odorant signals in the lipid rafts of olfactory cilia.

Key words: olfactory sensory neuron; olfactory cilia; stomatin; MEC-2; lipid rafts; adenylyl cyclase; caveolin
The vertebrate olfactory system can discriminate hundreds of thousand of different odorants with odorant receptor (OR) molecules expressed in the olfactory sensory neurons (OSNs) within the olfactory epithelium (OE). Each OSN expresses only one member of the OR gene family in a monoallelic manner (Chess et al., 1994; Malnic et al., 1999; Serizawa et al., 2000; Ishii et al., 2001). The OSNs, expressing a given OR gene, project their axons to a pair of glomeruli: one on the lateral and the other on the medial side (Ressler et al., 1994; Vassar et al., 1994; Mombaerts et al., 1996). Thus, odorant stimuli that activate a specific set of OSNs in the OE are converted to a topographic map of activated glomeruli on the olfactory bulb (OB).

Odorant perception initiates when odorant molecules interact with ORs on the surface of OSNs (Kurahashi 1989; Firestein and Werblin, 1989, Lowe and Gold, 1991; Mori and Yoshihara, 1995; Friedrich and Korsching, 1997; Zhao et al., 1998; Touhara et al., 1999). The major pathway of olfactory transduction involves the OR molecule, G-protein comprising the $G_{\text {olf }}$ subunit, adenylyl cyclase type III (ACIII), which generates cAMP, and olfactoryspecific cyclic nucleotide-gated channel (OcNC), all of which are exclusively or predominantly expressed in OSNs and localized to the specialized chemosensory compartments, the olfactory cilia (Jones and Reed, 1989; Bakalyar and Reed, 1990; Dhallan et al., 1990; Reed 1992; Wong et al., 2000).

Received March 13, 2002; revised April 22, 2002; accepted April 29, 2002.

This work was supported by grants from Japan Science and Technology (JST) Corporation, Ministry of Education, Culture and Science, Mitsubishi Foundation, and Japan Foundation for Applied Enzymology. This project is the Core Research for Evolutional Science and Technology (CREST) funded by JST. R.H. is a postdoctoral fellow of the Japan Society for Promotion of Science. A.T. is supported by the Precursory Research for Embryonic Science and Technology (PRESTO) program of JST. We thank Dr. Tetsuo Yamamori and Hitomi Sakano for critical reading of this manuscript. The DNA Data Bank of Japan accession number for the sro sequence is AB085692.

Correspondence should be addressed to Dr. Hitoshi Sakano, Room 116, Science Building \#3, Department of Biophysics and Biochemistry, University of Tokyo, 2-11-16 Yayoi, Bunkyo-ku, Tokyo 113-0032, Japan. E-mail: sakano@mail.ecc.utokyo.ac.jp.

Copyright (C) 2002 Society for Neuroscience $\quad 0270-6474 / 02 / 225931-07 \$ 15.00 / 0$
To study the signaling and projection of OSNs, we prepared murine cDNA libraries from the OE and searched for genes that are specifically expressed in the OE. Among prospective clones, we have characterized a cDNA encoding a stomatin-related olfactory protein (SRO) that shares $82 \%$ amino acid sequence similarity with the mouse stomatin (Schlegel et al., 1996). Stomatin was first found in red blood cells with a defect that caused hemolytic anemia called stomatocytosis (Stewart et al., 1993). Stomatin is detected in various tissues other than red blood cells and appears to function as a negative regulator of univalent cation permeability (Delaunay et al., 1999). In contrast to the stomatin gene, the sro gene is expressed specifically in OSNs. Furthermore, the sro transcript is present in the mature OSNs in the main OE but not in the vomeronasal epithelium (VNE). Immunohistochemisty demonstrated that SRO is localized to the olfactory cilia of mature OSNs. Here, we report the initial characterization of the sro gene and discuss the possible roles of SRO in the signal transduction of OSNs.

\section{MATERIALS AND METHODS}

Cloning of the sro gene. Fluorescent differential display (FDD) was performed according to the published protocol (Ito et al., 1994). The prospective cDNA was cloned into a plasmid vector pGEM-T (Promega, Madison, WI). Full-length cDNA was isolated from the mouse OE cDNA library in a phage vector $\lambda$ ZAPII (Stratagene, La Jolla, CA) using the sro cDNA obtained by the FDD screening as a probe. The cDNA inserts were isolated by in vivo excision with the ExAssist helper phage (Stratagene). The 5'-upstream region of sro was isolated from the mouse genomic library in a phage vector $\lambda$ EMBL3-SP6/T7 (Clontech, Palo Alto, CA), using the sro cDNA as a probe.

Northern blot analysis. Poly $\left(\mathrm{A}^{+}\right)$RNAs from various mouse tissues were extracted with a Fast Track Kit (Invitrogen, San Diego, CA). Poly $\left(\mathrm{A}^{+}\right) \mathrm{RNA}, 3 \mu \mathrm{g}$ each, was electrophoresed in an agarose gel and transferred to Hybond $\mathrm{N}^{+}$membrane (Amersham Biosciences, Little Chalfont, UK). The ${ }^{32} \mathrm{P}$-labeled sro 3'-UTR region probe was prepared with Megaprime DNA labeling systems (Amersham Biosciences).

In situ hybridization. In situ hybridization was performed as described (Tsuboi et al., 1999). The mouse sro, OMP, and stomatin probe was prepared by RT-PCR using a pair of primers, sro F1 (5'-) and sro R1 (5'-), OMP F1 (5'-ccagaggtacctcagcagtg- $\left.3^{\prime}\right)$ and OMP R1 (5'- 
a $\operatorname{SRO}(\mathrm{M})$

Stomatin (M)

UNC-1 (C)

$M E C-2$ (C)

Podocin (H)

\section{SRO (M) \\ Stomatin (M) \\ UNC-1 (C) \\ MBC- 2 (C)}

Podocin (H)

SRO (M)

Stomat in (M)

UNC- 1 (C)

MBC- 2 (C)

Podocin (H)

SRO (M)

Stomat in (M)

UNC-1 (C)

$M B C-2(C)$

Podocin (H)

$\mathrm{SRO}(\mathrm{M})$

Stomatin (M)

UNC-1 (C)

$\mathrm{MBC}-2(\mathrm{C})$

Podocin (H)

$\mathrm{SRO}(\mathrm{M})$

Stomat in (M)

UNC-1 (C)

$M B C-2$ (C)

Podocin (H) $\begin{array}{ll} & \\ \text { STSSDEVENMATRTLQQLEESTSIISANSDDDSVKKEKOAEKDVEKGNGKEEKANIONEF } 114\end{array}$ RQEAPEPSGSGRAGTPGEPRAPAATVVDVDEVRGSGEEGTEVVALLESERPEEGTKSSGL 98

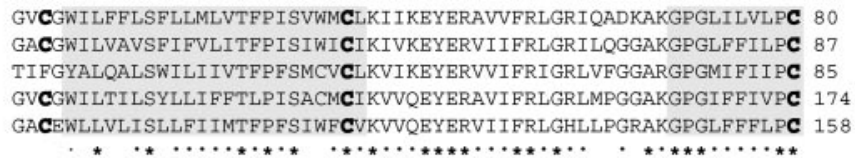

IDVFVKVDLRTVTCNIPPOEILTRDSVTTOVDGVVYYRIYSAVSAVANVNDVHOATFLLA 140 TDSFI KVDMRT I SFD I P PQEVLTKDSVTI SVDGVVYYRVONATLAVANITNADSATRLLA 147 IDTYRKIDLRVVSYAVPPQEILSKDSVTVSVDAVVYFRTSDPIASVNNVDDAIYSTKLLA 145 IDTYRKVDLRVLSFEVPPQEILSKDSVTVAVDAVVYFRI SNATI SVTNVEDAARSTKLLA 234 LDTYHKVDLRLQTLBI PFHEIVTKDMFI MEIDAICYYRMENASLLLSSLAHVSKAVQFLV 218

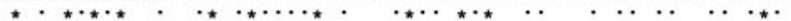

QTTLRNVLGTQTLSQILSGREEIAHSIQTLLDDATELWGIRVARVEIKDVRI PVQLQRSM 200 OTTLRNALGTKNLSQI LSDREEI AHHMOSTLDDATDDWGIKVERVEI KDVKLPVQLQRAM 207 QTTLRNALGMKTLTEMLTEREAIAQLCETILDEGTEHWGVKVERVEVKDIRLPQQLTRAM 205 QTTLRNILGTKTLAEMLSDREAISHQMQTTLDEATEPWGVKVERVEVKDVRLPVQLQRAM 294 QTTMKRLLAHRSLTEILLARKSIAODAKVALDSVTCIWGIKVERIEI KDVRLPAGLQHSL 278

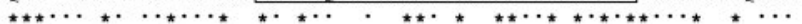

AAEAEATREARAKVLAAEGEMNASKSLKSASMVVAESPVALQLRYLQTLTTVATEKNSTI 260 AAEAEAAREARAKVIAAEGEMNASRALKEASMVITESPAALQLRYLOTLTTIAAEKNSTI 267 AAEAEAAREARAKVVAAEGEOKASRALKEAADVIOANPVALQLRHLOALNSIAAEHNSTI 265 AAEAEAAREARAKVIVAEGEQKASRALKEAAEVIAESPSALQLRYLQTLNSISAEKNSTI 354 AVEAEAQRQAKVRMIAAEAEKAASESLRMAAEI LSGTPAAVQLRYLHTLQSLSTEKPSTV 338

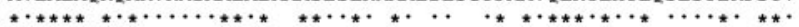

VFPLPMNILEGIGGISYGNNKKVTAKA VFPLPVDMLQGIMGSNH VFPVPVEMFGAFMKKDQ IFPFPIDLLSAFLQRTPPKVEEPPSLPKKIRSCCLYKYPDWVQGMVGSEGGGGHGHSHGG 414 VLPLPFDLLNCLSSPSNRTQGSLPFPSPSKPVEPLNPKKKDSPML - . . . . . . . 383 b

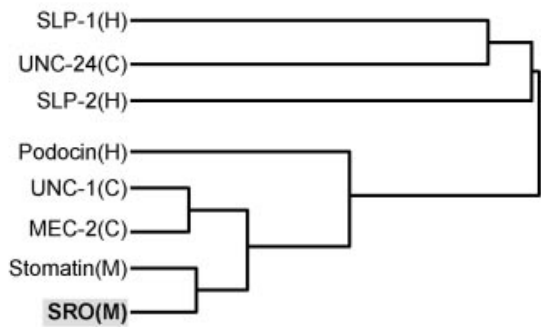

C

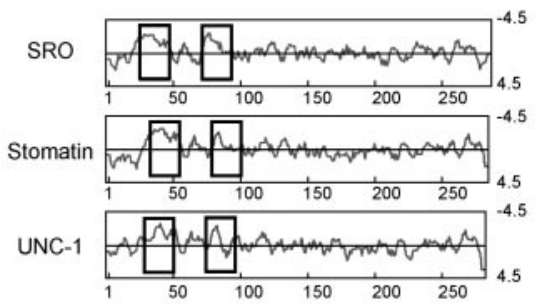

d

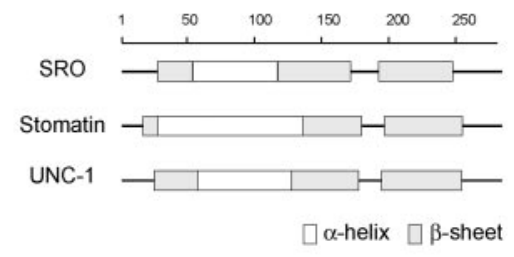

Figure 1. Comparison of stomatin-family proteins. $a$, The predicted amino acid sequence of SRO compared with those of stomatin-family proteins. Amino acid sequences are shown in the single-letter code. Putative membrane-spanning domains are shaded. The stomatin signature sequence is boxed. Consensus cysteine residues for palmitoylation at positions 23,46 , and 80 are indicated by bold-faced letters. Asterisks indicate conserved residues with identical amino acids. Dots indicate conserved amino acid residues with similar properties. Sources of the genes are shown as $C$. elegans $(C)$, mouse $(M)$, and human $(H) . b$, Dendrogram of stomatin-family proteins. Stomatin-family proteins from the mouse $(M)$, human $(H)$, and $C$. elegans $(C)$ were analyzed by the CLUSTAL procedure. The lengths of branches are proportional to the sequence differences. The mouse SRO and stomatin belong to the cluster of UNC-1 and MEC-2 of $C$. elegans. $c$, Hydrophobicity profiles for the mouse SRO, mouse stomatin, and $C$. elegans UNC-1 using the Kyte-Doolittle algorithm. Vertical axis indicates hydrophobicity. Hydrophobic transmembrane regions are in boxes. Residue numbers are indicated. $d$, Secondary structures of SRO, stomatin, and UNC-1. Regions rich in the $\beta$-sheets and $\alpha$-helices are indicated by shaded and open bars, respectively. Residue numbers are shown on the top.

ggagggcacacagtctttat- $\left.3^{\prime}\right)$, and stomatin F1 (5'-ccaccattgtcttccctctg- $\left.3^{\prime}\right)$ and stomatin R1 (5'-gtctaggctgtgtccettgc- $\left.3^{\prime}\right)$. The sro probe was generated from the cDNA clone containing the $3^{\prime}$-untranslated sequence. Each PCR-amplified cDNA fragment was cloned into pGEM-T vector and sequenced. cRNA probes were labeled with digoxigenin (DIG)-UTP using DIG-RNA labeling kit (Roche).

Antibody production. Polyclonal antibodies for the mouse SRO were generated using the $\mathrm{N}$-terminal peptide as an antigen (amino acid residues 1-19 and a cysteine: MDSPEKLEKNNLVGTNKSR-C). The peptide was conjugated to keyhole limpet hemocyanin using the Inject Maleimide-Activated mcKLH Kit (Pierce, Rockford, IL) and injected into two guinea pigs. After three rounds of booster injection, whole bleeding was performed on the animal. Anti-SRO antibodies were purified with a HiTrap affinity column (Amersham Biosciences).

Isolation of olfactory cilia from the $O E$. Olfactory cilia were prepared with the calcium shock method as described previously (Anholt et al., 1986). After washing the OE in ice-cold Ringer's solution, the tissue was gently stirred at $4^{\circ} \mathrm{C}$ for $20 \mathrm{~min}$ in the same solution supplemented with $10 \mathrm{~mm} \mathrm{CaCl} 2$. The deciliated $\mathrm{OE}$ was removed by centrifugation at $7700 \times g$ for $10 \mathrm{~min}$. The supernatant was further centrifuged at $27,000 \times g$ for $10 \mathrm{~min}$ to collect detached cilia. The pellet (cilia) was resuspended in hypotonic TME buffer $(10 \mathrm{~mm}$ Tris- $\mathrm{HCl}, \mathrm{pH} 7.4,3 \mathrm{~mm}$ $\mathrm{MgCl} 2,2 \mathrm{~mm}$ EGTA) and stored at $-70^{\circ} \mathrm{C}$.

Expression of SRO-green fluorescent protein fusion protein in human embryonic kidney 293 cells. The sro coding sequence flanked by the EcoRI (5') and SalI (3') ends was amplified with a pair of primers, $5^{\prime}$-gaattcatggattcaccggagaaact- $3^{\prime}$ and $5^{\prime}$-gtcgacttggctttagcagtgaccttct- $3^{\prime}$. The amplified fragment was cloned into a plasmid vector pEGFP-N1
(Clontech) and transfected into human embryonic kidney 293 (HEK293) cells using lipofectamine plus reagent (Invitrogen). After $3 \mathrm{~d}$ of incubation, the transfected and nontransfected (mock) cells were harvested, dissolved in SDS sample buffer, and applied to SDS-PAGE.

Western blot and immunoprecipitation analyses. For subcellular fractionation, the mouse OE was homogenized in PBS with protease inhibitors. After unbroken cells and nuclei were removed by centrifugation at $500 \times g$ for $5 \mathrm{~min}$, the supernatant was collected and recentrifuged at $2000 \times g$ for $15 \mathrm{~min}$. The resulting supernatant was further centrifuged at $100,000 \times g$ for $60 \mathrm{~min}$. The pellet (membrane) and supernatant fractions were separated by SDS-PAGE and transferred to Immobilon $\mathrm{P}$ membrane (Millipore, Bedford, MA).

The membrane fraction of the OE was incubated in PBS containing $1 \%$ Triton $\mathrm{X}-100$ at $0^{\circ} \mathrm{C}$ for $15 \mathrm{~min}$. Triton-soluble and -insoluble fractions were separated by centrifugation at $30,000 \times g$ for $30 \mathrm{~min}$ at $4^{\circ} \mathrm{C}$. An aliquot of the Triton-insoluble fraction was lysed for $10 \mathrm{~min}$ on ice in immunoprecipitation buffer (50 mm Tris- $\mathrm{HCl}, \mathrm{pH} 7.4,100 \mathrm{~mm} \mathrm{NaCl}, 1$ $\mathrm{mm}$ phenylmethylsulfonyl fluoride, and $10 \mu \mathrm{g} / \mathrm{ml}$ each of aprotinin, leupeptin, and pepstatin A) supplemented with $60 \mathrm{~mm} n$-octyl glucopyranoside. The lysate was centrifuged at $12,000 \times g$ for $15 \mathrm{~min}$ at $4^{\circ} \mathrm{C}$. The supernatant was incubated overnight at $4^{\circ} \mathrm{C}$ with anti-SRO guinea pig serum conjugated with protein $\mathrm{G}$ Sepharose (Amersham Biosciences), using preimmune guinea pig serum as a control. The amounts of IgG in control guinea pig serum and anti-SRO antibodies were quantified by Western blotting, and the same amounts of antibodies were used for immunoprecipitation experiments. Similar experiments were performed with anti-ACIII and anti-caveolin-1 (cav-1) (Santa Cruz Biotechnology, Santa Cruz, CA) antibodies. After immunoprecipitated samples were 
a

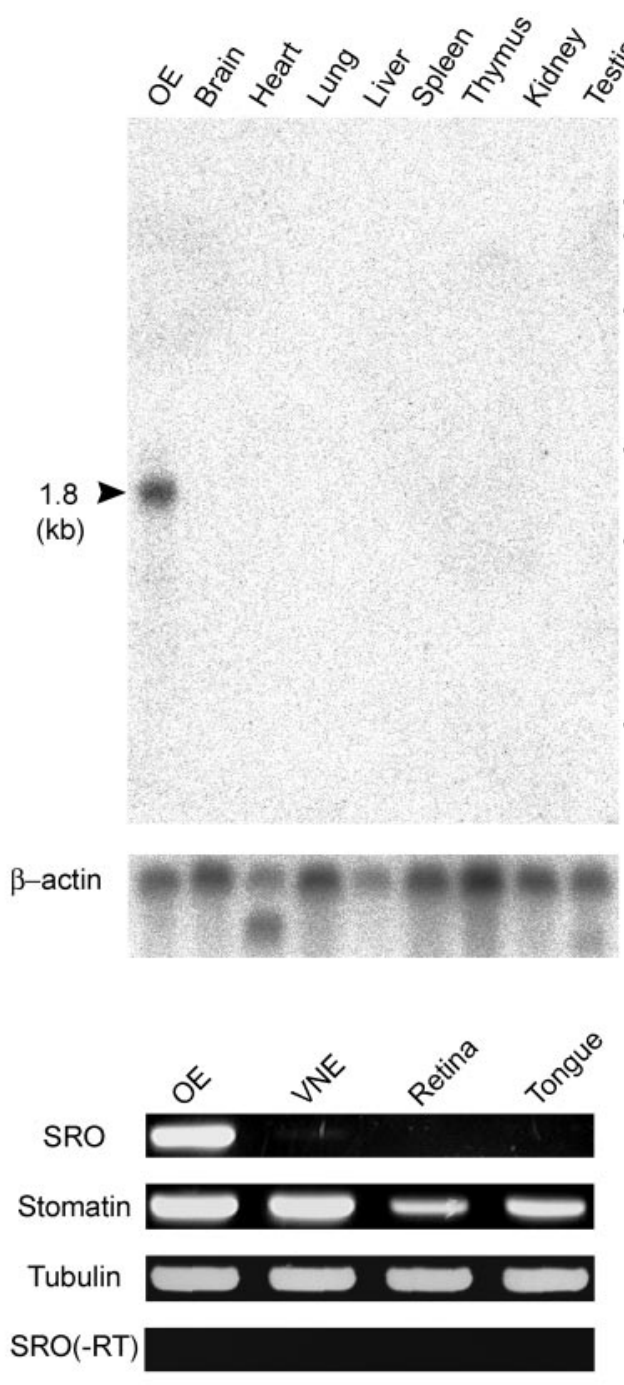

$-9.5$

$-7.5$

$-4.4$

$-2.4$

$-1.4$

$-0.24$

b

consensus
ACIII
Golf
OcNC
OMP (distal)
OMP (proximal)
mouse SRO
human SRO

YTCCCYRGGGAR
GTATATTTCCCTTGAGGAGAGAT
GACCAATTCCCCCAAGAATCCT
GGGAGAGTCCCTAGGGAGCTTGG
TCACATCTCCCAGGGGAGGTGGA
GCTCTGGTCCCCAAGGAGCCTGT
TTACTACTCCTCAGGGTGTACGC
GCTTCCCTCACCAGGGTAACTAC

Figure 2. OE-specific transcription of the sro gene. a, Northern blot analysis of the sro transcripts. Poly $\left(\mathrm{A}^{+}\right)$RNA samples isolated from various tissues were electrophoresed in an agarose gel, transferred to nylon membranes, and hybridized with ${ }^{32} \mathrm{P}$-labeled sro cDNA. Positions of size markers $(k b)$ are indicated. The same membrane was washed and rehybridized with the $\beta$-actin probe. $b$, RT-PCR of the sro transcript. Total RNA was isolated from the OE, VNE, retina, and tongue. Samples were treated with RNase-free DNase I and then reverse transcribed with random hexamer primers. PCR was performed with the sro, stomatin, and tubulin primers. $c$, Olf- 1 binding motifs. Upstream sequences are compared for various olfactory-specific genes encoding adenylyl cyclase type III $(A C I I I), \mathrm{G}_{\text {olf }}$, olfactory-specific cyclic nucleotide-gated channel $(O c N C)$, olfactory marker protein $(O M P)$, and stomatin-related olfactory protein $(S R O)$. Olf-1 binding motifs are shaded. The consensus sequence is shown on the top.
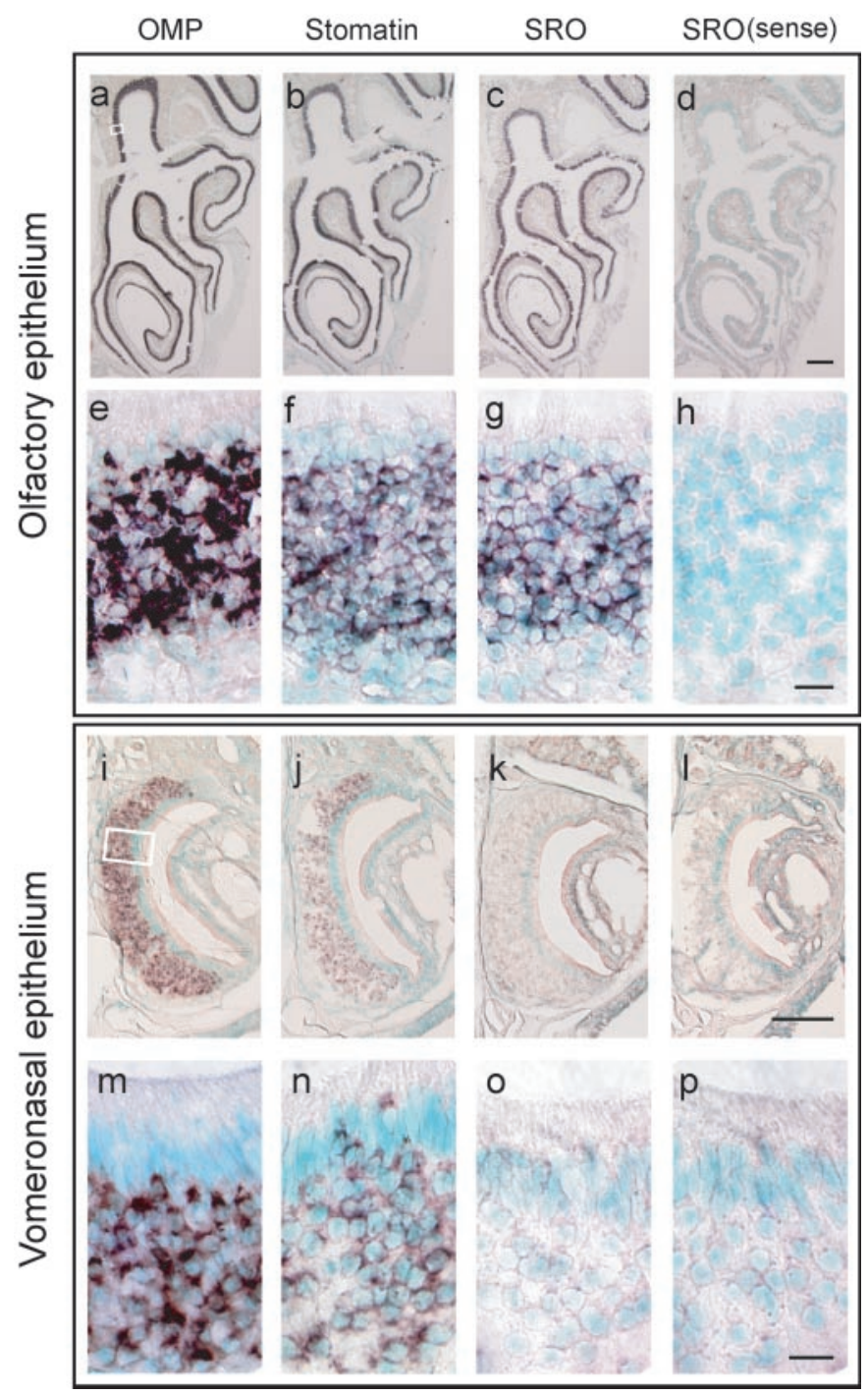

Figure 3. In situ hybridization of the olfactory and vomeronasal epithelia. Coronal sections of the mouse OE and VNE were hybridized with the DIG-labeled antisense probes of $\operatorname{OMP}(a, e, i, m)$, stomatin $(b, f, j, n)$, and sro $(c, g, k, o)$. The sense probe of sro was also hybridized as a negative control $(d, h, l, p)$. Both the low $(a-d, i-l)$ and high $(e-h, m-p)$ magnification view are shown. Enlarged areas are indicated by a box in $a$ and $i$. The sro mRNA was detected in the mature OSNs in all four zones of the $\mathrm{OE}(c, g)$. In the vomeronasal neurons, stomatin mRNA $(j, n)$ and OMP mRNA $(i, m)$ were detected, whereas the sro mRNA $(k, o)$ was not.

washed with immunoprecipitation buffer three times, bound proteins were eluted with SDS-PAGE sample buffer. The eluted samples were subjected to SDS-PAGE and subsequently to immunoblotting. As a negative control, anti-transferrin receptor antibody (Zymed Labs, San Francisco, CA) was used in Western blotting of the immunoprecipitated samples.

Various tissues of the adult mouse were homogenized in PBS buffer containing $2 \%$ SDS. After the protein concentrations were measured, samples $(\sim 1 \mu \mathrm{g}$ each) were separated by SDS-PAGE and transferred to the membrane.

Immunohistochemistry. Frozen coronal sections of the mouse $\mathrm{OE}$ and $\mathrm{OB}\left(10 \mu \mathrm{m}\right.$ thick) were fixed in acetone/methanol $(1: 1)$ at $-20^{\circ} \mathrm{C}$ for 15 min, treated with $0.2 \mathrm{~N} \mathrm{HCl}$ at room temperature for $10 \mathrm{~min}$, and washed in PBS three times (5 min each) at room temperature. Immunostaining was performed with the Vectastain $\mathrm{ABC}$ kit (Vector Laboratories, Burlingame, CA). For immunostaining, sections on the slide glasses were blocked with $1 \times$ casein solution (Vector Laboratories) and treated with antisera against $\mathrm{N}$-terminal peptide of SRO (diluted 1:1000 in $1 \times$ casein solution) at $4^{\circ} \mathrm{C}$ overnight. After they were washed in PBS three times (5 

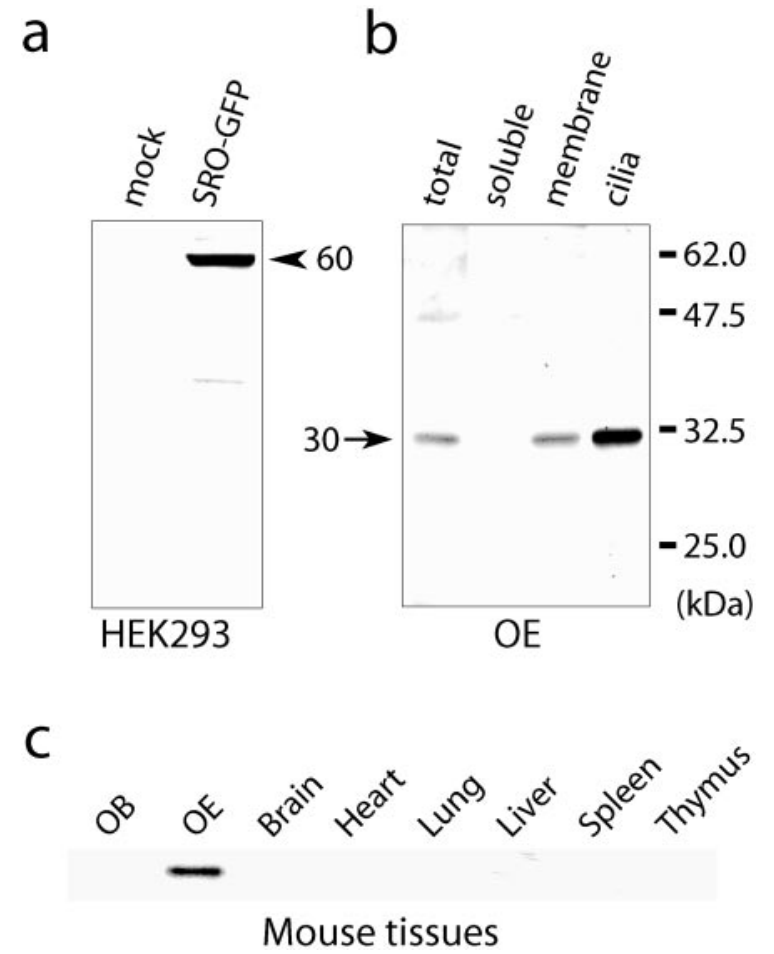

Figure 4. Western blot analyses of SRO. $a$, Detection of the SRO-GFP fusion protein. Cell lysates of HEK293 (mock) and HEK293 tranfected with the $s r o-G F P$ gene $(S R O-G F P)$ were separated by SDS-PAGE and subjected to Western blotting with polyclonal antibodies against the $\mathrm{N}$-terminal peptide of SRO. A $60 \mathrm{kDa}$ band (arrowhead) of the SRO-GFP fusion protein and a few fainter bands representing the degradation products were detected in the transfected cells. $b$, Detection of the endogenous SRO. Subcelluler fractions of the OE (soluble, membrane, and olfactory cilia) were separated by SDS-PAGE and analyzed by immunoblotting with anti-SRO polyclonal antibodies. A $30 \mathrm{kDa}$ band (arrow), representing the native SRO, is present in the membrane and cilia fractions. $c$, OE-specific expression of $30 \mathrm{kDa}$ SRO. Cell extracts from various tissues of the adult mouse were separated by SDS-PAGE and immunoblotted with anti-SRO polyclonal antibodies. The $30 \mathrm{kDa}$ band of SRO is detected only in the OE.

min each), the slides were treated with biotinylated secondary antibodies for $30 \mathrm{~min}$, washed three times (5 min each) in PBS, and reacted with the Vectastain ABC-AP reagent (Vector Laboratories) for $30 \mathrm{~min}$. After they were washed twice ( 5 min each) in PBS, the slides were incubated in $100 \mathrm{~mm}$ Tris-HCl, pH 9.5, containing 5-bromo-4-chloro-3-indorylphosphate/4-nitroblue tetra-zolium chloride substrate.

Analysis of membrane fractions of olfactory cilia. Flotation analysis of the cilia membranes was performed as reported by Brückner et al. (1999). Cilia of OSNs were isolated from the OE of adult mice (12 weeks old) and lysed in $150 \mu \mathrm{l}$ of TXNE buffer (50 mM Tris-HCl, pH 7.4, $150 \mathrm{~mm}$ $\mathrm{NaCl}, 5 \mathrm{~mm}$ EDTA, and $1 \%$ Triton X-100) supplemented with $10 \mathrm{mg} / \mathrm{ml}$ of leupeptin, aprotinin, and pepstatin, and $1 \mathrm{~mm}$ PMSF. The lysate was passed through a 22 gauge syringe three times and incubated at $0^{\circ} \mathrm{C}$ for $20 \mathrm{~min}$ on a rocking platform. The extract was mixed with $210 \mu \mathrm{l}$ of $60 \%$ OptiPrep (Nycomerd Pharma, Oslo, Norway) in 1\% Triton X-100 and put in an Sw55Ti ultracentrifuge tube (Beckmann, Palo Alto, CA), followed by overlay with $3.5 \mathrm{ml}$ of $30 \%$ OptiPrep in TXNE and $0.4 \mathrm{ml}$ of TXNE. After centrifugation at $200,000 \times g$ at $4^{\circ} \mathrm{C}$ for $4 \mathrm{hr}$, seven fractions were collected from the top, precipitated with trichloroacetic acid, washed with acetone, and air dried. An aliquot of each fraction was analyzed by Western blotting.

Stimulation of cAMP production in olfactory cilia. Experiments were performed according to the instructions of SpinZyme acidic alumina devices (Pierce). Isolated cilia membranes were incubated with either anti-SRO antibodies or preimmune guinea pig $\operatorname{IgG}$ at $0^{\circ} \mathrm{C}$ for $15 \mathrm{~min}$. The sample without antibodies was also examined as a control. For cAMP stimulation, cilia fractions $(15 \mu \mathrm{g}$ protein in each reaction) were dissolved in $50 \mu \mathrm{l}$ of reaction buffer containing 8 mM HEPES, pH 7.4, 1.6 $\mathrm{mm} \mathrm{MgCl}_{2}, 0.2 \mathrm{~mm} \mathrm{IBMX}, 80 \mu \mathrm{g} / \mathrm{ml}$ BSA, $40 \mu \mathrm{M}$ cAMP, 0.4 mм ATP, $4 \mathrm{~mm}$ creatine phosphate, $40 \mathrm{U} / \mathrm{ml}$ creatine phosphokinase, $8 \mu \mathrm{M}$ GTP, and $0.4 \mathrm{mM}$ dithiothreitol. To stimulate the cAMP production, either 10 $\mu \mathrm{M}$ GTP $\gamma \mathrm{S}$ or $5 \mu \mathrm{M}$ forskolin was added. The reaction was performed at $37^{\circ} \mathrm{C}$ for $20 \mathrm{~min}$ in the presence of $\alpha^{-}{ }^{32} \mathrm{P}$-ATP, and terminated by adding $10 \mu \mathrm{l}$ of carrier solution containing $5 \mathrm{mg} / \mathrm{ml}$ cAMP (sodium salt) and $0.5 \mathrm{~N} \mathrm{HCl}$. The amounts of cAMP were measured with SpinZyme acidic alumina devices (Pierce).

\section{RESULTS \\ Cloning of cDNA encoding the stomatin-related olfactory protein, SRO}

A cDNA clone coding for the rat SRO was isolated from the OE of 3-week-old animals by the differential display method. To determine the tissue specificity of sro expression, we performed in situ hybridization of the rat olfactory tissues with the sro probe. Strong hybridization signals were detected in the tissue sections of the OE but not of the brain. By assembling contigs of the mouse sro cDNAs isolated with the rat probe, the full-length mouse cDNA was estimated to be $1.83 \mathrm{~kb}$. The mouse sro gene encodes a protein of 287 amino acid residues with a calculated molecular weight of $32 \mathrm{kDa}$. Homology search with the Protein Identification Resource database revealed that the mouse sro gene is most homologous to the mouse stomatin gene (Fig. 1a). The mouse SRO shares $82 \%$ sequence similarity with the mouse stomatin, $78 \%$ with the C. elegans MEC-2, and $77 \%$ with the $C$. elegans UNC-1.

\section{The predicted amino acid sequence of SRO}

The deduced amino acid sequence of SRO was compared with the published sequences of the mouse stomatin, UNC-1 and MEC-2 of C. elegans, and human podocin (Fig. 1a). These proteins all share the consensus sequence, $\mathrm{RX}_{2}(\mathrm{~L} / \mathrm{I} / \mathrm{V})(\mathrm{S} / \mathrm{A} / \mathrm{N}) \mathrm{X}_{6}(\mathrm{~L} / \mathrm{I} /$ $\mathrm{V}) \mathrm{DX}_{2} \mathrm{TX}_{2} \mathrm{WG}(\mathrm{L} / \mathrm{I} / \mathrm{V})(\mathrm{K} / \mathrm{R} / \mathrm{H})(\mathrm{L} / \mathrm{I} / \mathrm{V}) \mathrm{X}(\mathrm{K} / \mathrm{R})(\mathrm{L} / \mathrm{I} / \mathrm{V}) \mathrm{E}(\mathrm{L} / \mathrm{I} /$ $\mathrm{V})(\mathrm{K} / \mathrm{R})$, which defines the stomatin-family proteins. A CLUSTAL analysis revealed that $\mathrm{SRO}$ belongs to the same cluster as stomatin, MEC-2, and UNC-1 (Fig. 1b). From the hydrophobicity profile (Fig. 1c) and motif search, SRO was shown to contain two Nterminal hydrophobic domains and three consensus sequences of Cys for palmitoylation at positions 23, 46, and 80 (Snyers et al., 1999). These features, characteristic of the stomatin-family proteins, suggest that SRO can intercalate directly into the lipid bilayer, like other stomatin-family proteins. SRO also contains a unique combination of $\beta$-sheet-rich and $\alpha$-helix-rich structures that is commonly found in other stomatin-family proteins (Fig. 1d).

\section{The sro gene is specifically expressed in the OE}

To study the tissue distribution of sro mRNA, we performed Northern blot analysis of poly $\left(\mathrm{A}^{+}\right) \mathrm{RNA}$ extracted from the $\mathrm{OE}$, brain, heart, lung, liver, spleen, thymus, kidney, and testis. The sro mRNA of $1.8 \mathrm{~kb}$ was detected in the OE but not in other tissues examined so far (Fig. 2a). The size of the transcript $(1.8 \mathrm{~kb})$ indicates that the isolated cDNA clone contains the full-length sequence of sro mRNA. RT-PCR analyses demonstrated that the sro gene is expressed specifically in the OE, whereas the stomatin transcript can also be found in other tissues, including the VNE, retina, and tongue (Fig. $2 b$ ).

The Olf-1 motif is commonly found in the promoter region of genes involved in olfactory signaling (Kudrycki et al., 1993; Wang and Reed, 1993; Wang et al., 1993). To examine whether the Olf-1 motif is present in the sro gene, we isolated the promoter region of the mouse genomic sro gene and determined its nucleotide sequence. The human sro sequence was also obtained from the 

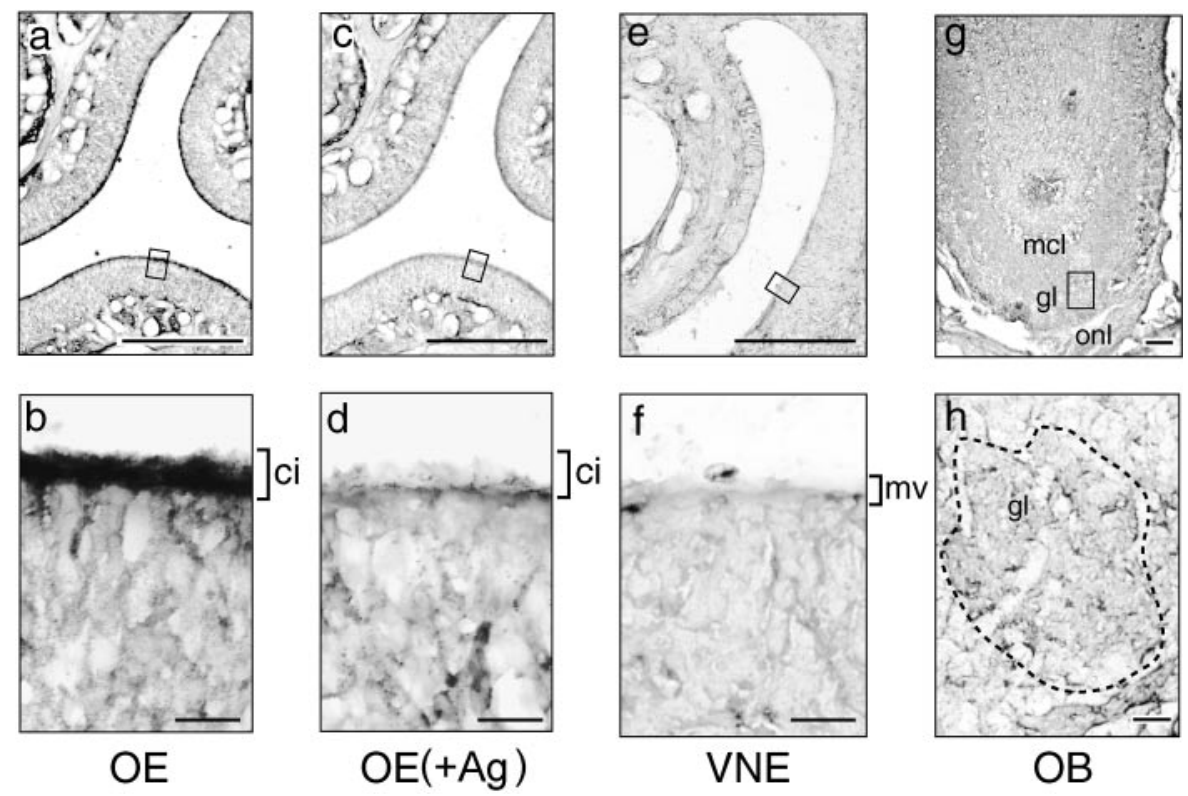

Figure 5. Immunohistochemical detection of SRO. Tissue sections (16 $\mu \mathrm{m}$ thick) of the mouse main olfactory epithelium $(O E)(a, b)$, vomeronasal epithelium $(V N E)(e, f)$, and olfactory bulb $(O B)(g, h)$ were analyzed with anti-SRO polyclonal antibodies. As a negative control, the $\mathrm{OE}$ section $(c, d)$ was stained in the presence of the peptide antigen $(+A g)$. Low- and highmagnification views are shown in the top and bottom panels, respectively. Immunostaining signals were detected in the olfactory cilia ( $c i$ ) of OSNs in the OE, but not in the microvilli ( $m v)$ of the VNE. The mitral cell layer $(\mathrm{mcl})$, glomerulus layer $(\mathrm{gl})$, and olfactory nerve layer (onl) are indicated in $g$. human genome database (clone RP11-50D16: GenBank accession no. AL445590). In both mouse and human sro genes, Olf-1 binding sequences were found in the putative promoter regions (Fig. 2c).

\section{The sro gene is transcribed in the main OE but not in the VNE}

To examine the sro expression in the olfactory tissues, we performed in situ hybridization using DIG-labeled antisense probes (Fig. 3). In the main OE, both sro and stomatin transcripts were detected in all four zones, specifically in the OSN layer where the OMP gene is expressed. No hybridization signals were found in the supporting cells, basal cells, or GAP43-positive immature OSNs in the main OE. In the VNE, stomatin mRNA was detected in the vomeronasal neurons. However, the sro transcript was not detected in the VNE.

\section{SRO is localized to olfactory cilia of OSNs}

To study the localization of SRO protein in OSNs, polyclonal antibodies were raised against the region of the $\mathrm{N}$ terminus of SRO, not homologous to that of stomatin. For Western blotting, total cell lysates of HEK293 (mock) and HEK293 expressing the SRO fusion protein with green fluorescent protein (GFP) were separated by SDS-PAGE (Fig. 4a). Anti-SRO antibodies detected a strong band of the $60 \mathrm{kDa}$ protein and a few fainter bands of possible degradation products. The observed molecular weight $(60 \mathrm{kDa})$ corresponds to that calculated for the SRO-GFP fusion protein. Immunoblot analysis also detected the endogenous SRO of $30 \mathrm{kDa}$ in the OE (Fig. 4b). To examine the subcellular localization of the native SRO, the adult OE was fractionated into the cytosol (soluble), membrane, and olfactory cilia fractions. SRO was detected in the membrane fraction and most significantly in the olfactory cilia (Fig. $4 b$ ). The SRO band of $30 \mathrm{kDa}$ was specifically found in the OE but not in other tissues, including the OB, brain, heart, lung, liver, spleen, and thymus (Fig. 4c).

Cellular localization of SRO was further examined by immunohistochemistry on fixed sections of the main OE, VNE, and $\mathrm{OB}$ isolated from the adult mouse (Fig. 5). In the main OE, staining signals were intense in most apical dendrites, including olfactory cilia, but were weak in the cell bodies of OSNs. The signals diminished when the peptide antigen was applied. Very weak signals were detected in the olfactory nerve and glomerular layers of the OB. Staining was not detected in the VNE, even in the microvilli of the vomeronasal neurons.

\section{Association of SRO with ACIII and caveolin-1}

Stomatin is one of the major integral membrane proteins of erythrocyte lipid rafts (Salzer and Prohaska, 2001), which are characterized by the insolubility in cold nonionic detergents and flotation on density gradients (Hooper, 1997). To examine whether SRO is also present in lipid rafts, Triton X-100-soluble and -insoluble fractions of the cilia membrane were separated in the flotation gradient and subjected to Western blotting. It has been reported that cav-1 is found in lipid rafts, whereas transferrin receptor (TrfR) is not (Smart et al., 1995). As shown in Figure $6 a$, SRO was detected in the low-density fractions that contain cav- 1 but not TrfR. These results indicate that SRO is localized in lipid rafts.

Because cav-1 is known to form a complex with other signaling components, e.g., ACIII (Schreiber et al., 2000), we tested whether SRO is associated with the signaling complex by immunoprecipitation with anti-cav-1, anti-ACIII, and anti-SRO antibodies. As shown in Figure $6 b$, Western blot analysis revealed that the immunoprecipitate with anti-SRO antibodies contains ACIII and cav-1. Guinea pig IgG as a control did not give any background. In contrast, TrfR was not detected in coprecipitates of SRO, cav-1, or ACIII (Fig. 6b).

It has been reported that ACIII and cav-1 mediate the production of cAMP in the olfactory cilia (Schreiber et al., 2000). Because SRO was shown to interact with both ACIII and cav-1, we examined the effect of anti-SRO antibodies on the cAMP production in the cilia membrane fraction. As shown in Figure 7, SRO antibodies enhanced cAMP production when the cilia fraction was stimulated by GTP $\gamma \mathrm{S}$ and forskolin. Control antibodies, preimmune guinea pig IgG, did not affect the level of cAMP. These results indicate that SRO is associated with both ACIII and cav-1 in the lipid rafts of olfactory cilia and may play an important role in modulating the odorant signals. 
a
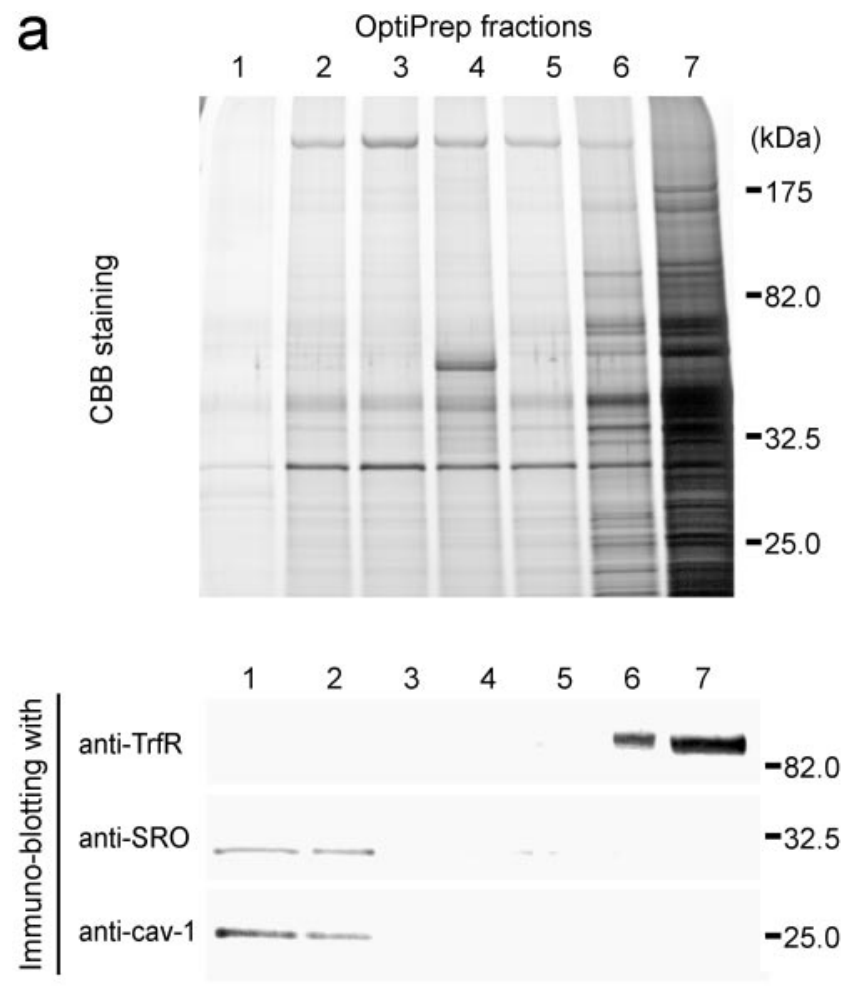

b

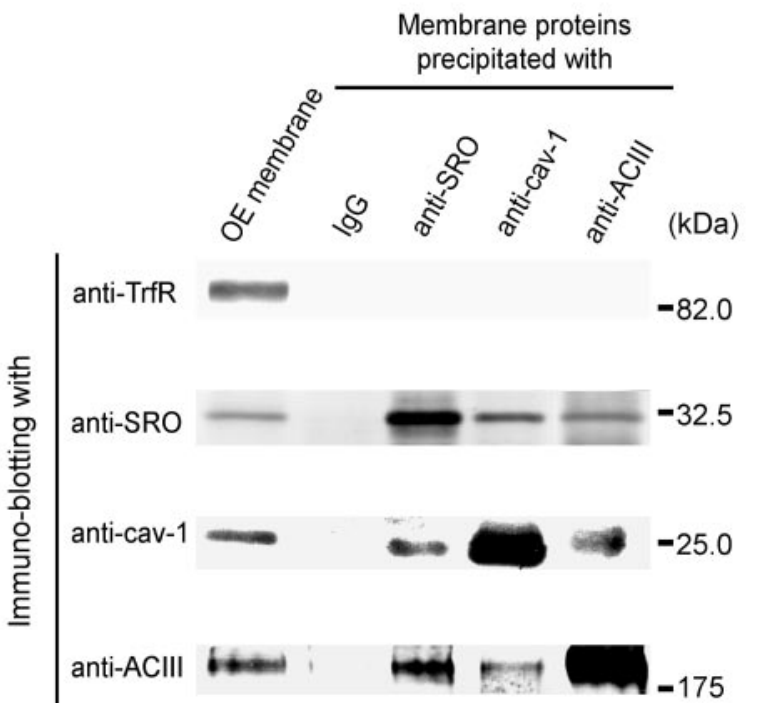

Figure 6. Association of SRO with ACIII and caveolin-1 in the lipid raft. $a$, Detection of SRO in the lipid rafts of olfactory cilia. Olfactory cilia were isolated from the OE and lysed with $1 \%$ Triton X-100. The lysate was fractionated in an OptiPrep flotation gradient. Seven fractions were collected from the top to the bottom and were separated by SDS-PAGE. Gels were stained with Coomassie Brilliant Blue $(C B B)$, transferred to an Immobilon-P membrane filter (Millipore), and subjected to immunoblotting using three different antibodies, anti-SRO, anti-caveolin-1 (cav-1), and anti-transferrin receptor ( $\operatorname{Tr} f R)$ antibodies. Cav-1 and TrfR serve as raft-associated and non-raft-associated controls, respectively. SRO and cav-1 were detected in the low-density fractions, 1 and 2 , whereas TrfR was detected in the high-density fractions, 6 and $7 . b$, Immunocoprecipitation of SRO with ACIII and caveolin-1. Triton-insoluble fractions of the OE membrane were solubilized with $n$-octyl glucopyranoside and precipitated with anti-SRO, anti-cav-1, or anti-ACIII antibodies. Guinea pig serum $(I g G)$ was used as a control. The precipitates were then analyzed by immunoblotting with anti-SRO, anti-cav-1, anti-ACIII, and anti-TrfR antibodies. OE membrane proteins without immunoprecipitation $(O E$

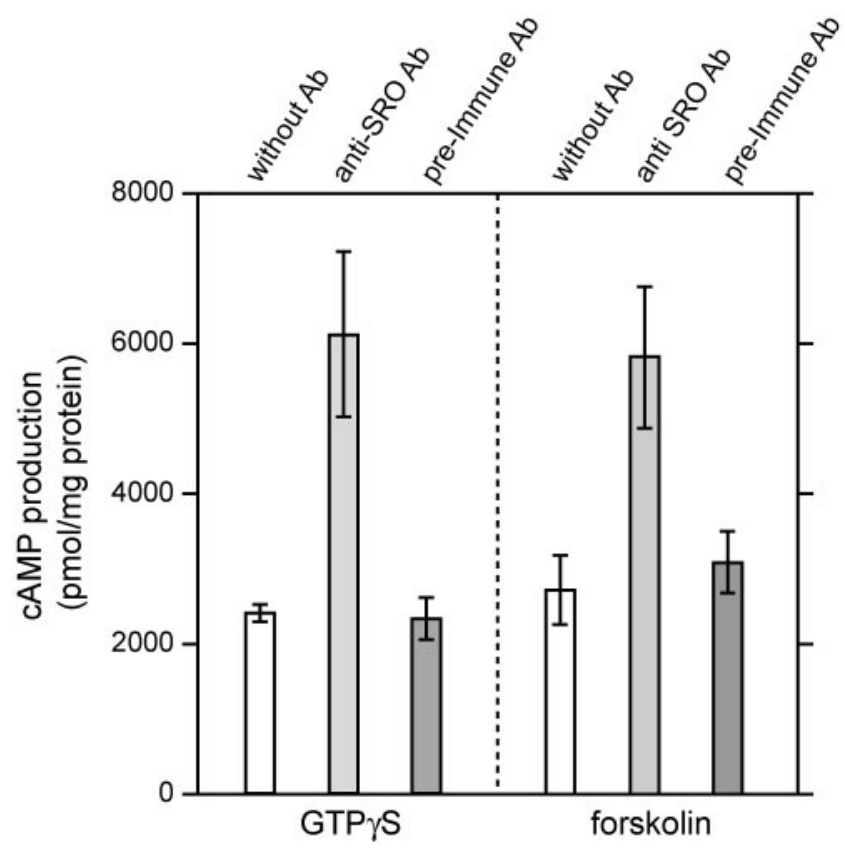

Figure 7. Enhancement of cAMP production in olfactory cilia. Isolated cilia were treated with anti-SRO antibodies (anti-SRO $A b)$ or with preimmune guinea pig $\operatorname{IgG}$ ( pre-Immune $A b$ ) at $0^{\circ} \mathrm{C}$ for $15 \mathrm{~min}$. Cilia samples without antibody treatment (without $A b$ ) were also examined. Production of cAMP was induced by either $10 \mu \mathrm{M}$ GTP $\gamma \mathrm{S}$ or $5 \mu \mathrm{M}$ forskolin and measured after incubation at $37^{\circ} \mathrm{C}$ for $20 \mathrm{~min}$. The vertical axis shows picomole amounts of cAMP per $1 \mathrm{mg}$ of cilia proteins ( pmol/mg protein). To examine whether the cAMP production was indeed enhanced by the SRO antibodies compared with preimmune Ab, Student's $t$ values were calculated (GTP $\gamma \mathrm{S}, p<0.004$; forskolin, $p<0.000001)$.

\section{DISCUSSION}

In the present study, we have isolated a novel cDNA clone encoding a stomatin-related olfactory protein, SRO, and characterized its expression by in situ hybridization and immunohistochemistry. SRO is specifically expressed in mature OSNs in the main OE but not in the VNE. This is in sharp contrast with stomatin, which is found in various neuronal and non-neuronal tissues: OE, VNE, tongue, and eye. Like other olfactory-specific genes, such as for OMP, $\mathrm{G}_{\mathrm{olf}}$, ACIII, and OcNC, the sro gene contains the Olf-1 binding motif in the upstream regulatory region (Kudrycki et al., 1993; Wang and Reed, 1993; Wang et al., 1993).

In C. elegans, two stomatin-related genes, unc-1 and mec-2, have been identified by the genetic method. Their relative expression pattern is somewhat similar to that between the stomatin and sro genes. In C. elegans, UNC-1 is widely present in the nervous system (Rajaram et al., 1999; Sedensky et al., 2001), whereas MEC-2 is expressed only in six mechano-transductive neurons and OSNs (Huang et al., 1995). The mec-2 mutants have been reported to show defective chemotaxis toward volatile odorants (Bargmann et al., 1993). Considering the high sequence homology and specific expression in OSNs, we predict that the mouse sro, like the mec-2 in C. elegans, plays important roles in olfactory signaling.

We have studied the subcellular localization of SRO by Western blotting and immunohistochemistry. Like other stomatin-family

$\leftarrow$

membrane) were also analyzed. Antibodies used for the immunoprecipitation are indicated on the top. On the left, antibodies for immunoblotting are shown. 
proteins, SRO is most likely a membrane protein, because two transmembrane domains were predicted from the cDNA sequence. Western blot analysis indicated that SRO is localized to the membrane fraction of olfactory cilia. Immunostaining with anti-SRO antibodies confirmed this notion. SRO shares structural features with other stomatin-family proteins, which consist of a short N-terminal domain, two transmembrane domains, and a large cytoplasmic C-terminal domain. Both the $\mathrm{N}$ - and $\mathrm{C}$-terminal domains of stomatin as well as those of SRO are cytosolic, suggesting that their transmembrane domains form a hairpin-like structure. Furthermore, SRO contains conserved cysteine residues within and adjacent to the transmembrane domains. It has been reported that stomatin forms a large homo-oligomeric complex via the $\mathrm{C}$ terminus, and that two of the cysteine residues in stomatin are palmitoylated (Snyers et al., 1999). These properties are thought to be important in increasing the affinity between stomatin and plasma membranes. Both stomatin and flotillin, which belong to the SPFH (stomatins, prohibitins, flotillins, and HflK/C) domain family (Tavernarakis et al., 1999), are major components of the erythrocyte lipid rafts, which are sphingolipid- and cholesterol-rich membrane microdomains. This structure acts as a platform for signals transduced through the lipid bilayer (Simons and Ikonen, 1997; Brown and London, 1998). It has been reported that some key components for the olfactory signaling, e.g., $\mathrm{G}_{\text {olf }}$, ACIII, and caveolins, are found in the lipid rafts of olfactory cilia (Schreiber et al., 2000). Our immunoprecipitation studies indicate that SRO is associated with ACIII and caveolin-1 in the lipid rafts. Furthermore, anti-SRO antibodies stimulated the cAMP production in the membrane fraction of olfactory cilia. It is possible that SRO is present in the lipid rafts of olfactory cilia, forming the supramolecular complex to generate odor-induced signals. However, it is yet to be clarified exactly how SRO is involved in olfactory signaling. Because sro expression is highly specific to the OSNs, knock-out studies and dominant-negative transgenic mice will be helpful in elucidating the function of SRO.

\section{REFERENCES}

Anholt RR, Aebi U, Snyder SH (1986) A partially purified preparation of isolated chemosensory cilia from the olfactory epithelium of the bullfrog, Rana catesbeiana. J Neurosci 6:1962-1969.

Bakalyar HA, Reed RR (1990) Identification of a specialized adenylyl cyclase that may mediate odorant detection. Science 250:1403-1406.

Bargmann CI, Hartwieg E, Horvitz HR (1993) Odorant-selective genes and neurons mediate olfaction in C. elegans. Cell 74:515-527.

Brown DA, London E (1998) Functions of lipid rafts in biological membranes. Annu Rev Cell Dev Biol 14:111-136.

Brückner K, Pablo Labrador J, Scheiffele P, Herb A, Seeburg PH, Klein R (1999) EphrinB ligands recruit GRIP family PDZ adaptor proteins into raft membrane microdomains. Neuron 22:511-524.

Chess A, Simon I, Cedar H, Axel R (1994) Allelic inactivation regulates olfactory receptor gene expression. Cell 78:823-834.

Delaunay J, Stewart G, Iolascon A (1999) Hereditary dehydrated and overhydrated stomatocytosis: recent advances. Curr Opin Hematol 6:110-114.

Dhallan RS, Yau KW, Schrader KA, Reed RR (1990) Primary structure and functional expression of a cyclic nucleotide-activated channel from olfactory neurons. Nature 347:184-187.

Firestein S, Werblin F (1989) Odor-induced membrane currents in vertebrate-olfactory receptor neurons. Science 244:79-82.

Friedrich RW, Korsching SI (1997) Combinatorial and chemotopic odorant coding in the zebrafish olfactory bulb visualized by optical imaging. Neuron 18:737-752.

Huang M, Gu G, Ferguson EL, Chalfie M (1995) A stomatin-like protein necessary for mechanosensation in C. elegans. Nature 378:292-295.

Hooper NM (1997) Glycosyl-phosphatidylinositol anchored membrane enzymes. Clin Chim Acta 266:3-12.

Ishii T, Serizawa S, Kohda A, Nakatani H, Shiroishi T, Okumura K, Iwakura Y, Nagawa F, Tsuboi A, Sakano H (2001) Monoallelic expression of the odourant receptor gene and axonal projection of olfactory sensory neurones. Genes Cells 6:71-78.

Ito T, Kito K, Adati N, Mitsui Y, Hagiwara H, Sakaki Y (1994) Fluo- rescent differential display: arbitrarily primed RT-PCR fingerprinting on an automated DNA sequencer. FEBS Lett 351:231-236.

Jones DT, Reed RR (1989) Golf: an olfactory neuron specific-G protein involved in odorant signal transduction. Science 244:790-795.

Kudrycki K, Stein Izsak C, Behn C, Grillo M, Akeson R, Margolis FL (1993) Olf-1-binding site: characterization of an olfactory neuronspecific promoter motif. Mol Cell Biol 13:3002-3014.

Kurahashi T (1989) Activation by odorants of cation-selective conductance in the olfactory receptor cell isolated from the newt. J Physiol (Lond) 419:177-192.

Lowe G, Gold GH (1991) The spatial distributions of odorant sensitivity and odorant-induced currents in salamander olfactory receptor cells. J Physiol (Lond) 442:147-168.

Malnic B, Hirono J, Sato T, Buck LB (1999) Combinatorial receptor codes for odors. Cell 96:713-723.

Mombaerts P, Wang F, Dulac C, Chao SK, Nemes A, Mendelsohn M, Edmondson J, Axel R (1996) Visualizing an olfactory sensory map. Cell 87:675-686.

Mori K, Yoshihara Y (1995) Molecular recognition and olfactory processing in the mammalian olfactory system. Prog Neurobiol 45:585-619.

Rajaram S, Spangler TL, Sedensky MM, Morgan PG (1999) A stomatin and a degenerin interact to control anesthetic sensitivity in Caenorhabditis elegans. Genetics 153:1673-1682.

Reed RR (1992) Signaling pathways in odorant detection. Neuron 8:205-209.

Ressler KJ, Sullivan SL, Buck LB (1994) Information coding in the olfactory system: evidence for a stereotyped and highly organized epitope map in the olfactory bulb. Cell 79:1245-1255.

Salzer U, Prohaska R (2001) Stomatin, flotillin-1, and flotillin-2 are major integral proteins of erythrocyte lipid rafts. Blood 97:1141-1143.

Schlegel W, Unfried I, Prohaska R (1996) Cloning and analysis of a cDNA encoding the BALB/c murine erythrocyte band 7 integral membrane protein. Gene 178:115-118.

Schreiber S, Fleischer J, Breer H, Boekhoff I (2000) A possible role for caveolin as a signaling organizer in olfactory sensory membranes. J Biol Chem 275:24115-24123.

Sedensky MM, Siefker JM, Morgan PG (2001) Model organisms: new insights into ion channel and transporter function. Stomatin homologues interact in Caenorhabditis elegans. Am J Physiol Cell Physiol 280:C1340-1348

Serizawa S, Ishii T, Nakatani H, Tsuboi A, Nagawa F, Asano M, Sudo K, Sakagami J, Sakano H, Ijiri T, Matsuda Y, Suzuki M, Yamamori T, Iwakura Y, Sakano H (2000) Mutually exclusive expression of odorant receptor transgenes. Nat Neurosci 3:687-693.

Simons K, Ikonen E (1997) Functional rafts in cell membranes. Nature 387:569-572.

Smart EJ, Ying YS, Mineo C, Anderson RG (1995) A detergent-free method for purifying caveolae membrane from tissue culture cells. Proc Natl Acad Sci USA 92: 10104-10108.

Snyers L, Umlauf E, Prohaska R (1999) Cysteine 29 is the major palmitoylation site on stomatin. FEBS Lett 449:101-104.

Stewart GW, Argent AC, Dash BC (1993) Stomatin: a putative cation transport regulator in the red cell membrane. Biochim Biophys Acta $1225: 15-25$

Tavernarakis N, Driscoll M, Kyrpides NC (1999) The SPFH domain: implicated in regulating targeted protein turnover in stomatins and other membrane-associated proteins. Trends Biochem Sci 24:425-427.

Touhara K, Sengoku S, Inaki K, Tsuboi A, Hirono J, Sato T, Sakano H, Haga T (1999) Functional identification and reconstitution of an odorant receptor in single olfactory neurons. Proc Natl Acad Sci USA 96:4040-4045.

Tsuboi A, Yoshihara S, Yamazaki N, Kasai H, Asai-Tsuboi H, Komatsu M, Serizawa S, Ishii T, Matsuda Y, Nagawa F, Sakano H (1999) Olfactory neurons expressing closely linked and homologous odorant receptor genes tend to project their axons to neighboring glomeruli on the olfactory bulb. J Neurosci 19:8409-8418.

Vassar R, Chao SK, Sitcheran R, Nunez JM, Vosshall LB, Axel R (1994) Topographic organization of sensory projections to the olfactory bulb. Cell 79:981-991.

Wang MM, Reed RR (1993) Molecular cloning of the olfactory neuronal transcription factor Olf-1 by genetic selection in yeast. Nature 364:121-126.

Wang MM, Tsai RY, Schrader KA, Reed RR (1993) Genes encoding components of the olfactory signal transduction cascade contain a DNA binding site that may direct neuronal expression. Mol Cell Biol 13:5805-5813.

Wong ST, Trinh K, Hacker B, Chan GC, Lowe G, Gaggar A, Xia Z, Gold GH, Storm DR (2000) Disruption of the type III adenylyl cyclase gene leads to peripheral and behavioral anosmia in transgenic mice. Neuron 27:487-497.

Zhao H, Ivic L, Otaki JM, Hashimoto M, Mikoshiba K, Firestein S (1998) Functional expression of a mammalian odorant receptor. Science 279:237-242. 